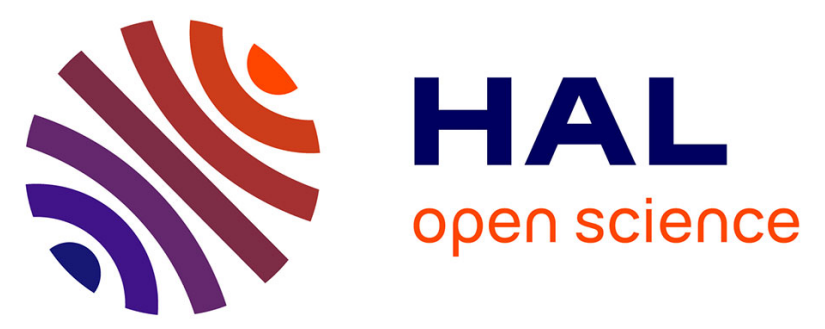

\title{
Contribution of Lightweight Revolving Laser Scanner, HiRes UAV LiDARs and photogrammetry for characterization of coastal aeolian morphologies
}

Manuel Garcin, Franck Desmazes, Alexandre Nicolae-Lerma, Loïc Gouguet, Valentin Météreau

\section{To cite this version:}

Manuel Garcin, Franck Desmazes, Alexandre Nicolae-Lerma, Loïc Gouguet, Valentin Météreau. Contribution of Lightweight Revolving Laser Scanner, HiRes UAV LiDARs and photogrammetry for characterization of coastal aeolian morphologies. Journal of Coastal Research, 2020, pp.11 - 15. 10.2112/SI95-0XX.1 . hal-02483237

\section{HAL Id: hal-02483237 https: / hal-brgm.archives-ouvertes.fr/hal-02483237}

Submitted on 5 Mar 2020

HAL is a multi-disciplinary open access archive for the deposit and dissemination of scientific research documents, whether they are published or not. The documents may come from teaching and research institutions in France or abroad, or from public or private research centers.
L'archive ouverte pluridisciplinaire HAL, est destinée au dépôt et à la diffusion de documents scientifiques de niveau recherche, publiés ou non, émanant des établissements d'enseignement et de recherche français ou étrangers, des laboratoires publics ou privés. 


\title{
Contribution of Lightweight Revolving Laser Scanner, HiRes UAV LiDARs and photogrammetry for characterization of coastal aeolian morphologies
}

Manuel Garcin ', Franck Desmazes ${ }^{1}$, Alexandre Nicolae-Lerma ${ }^{1}$, Loïc Gouguet ${ }^{2}$, Valentin Météreau²

1- BRGM (French Geological Survey), Risks and Prevention Division, Orléans, France

2- Office National des Forêts (French National Forest Agency), Nantes, France

\begin{abstract}
The monitoring of coastal dunes changes in a context of climate change is a major issue for assessment of coastal hazards. While shoreline retreat and beach erosion are generally well characterized within coastal observatories, the monitoring of dunes changes under aeolian-driven processes are frequently neglected. An innovative approach using several diachronic or synchronous acquisitions of UAV LiDAR, UAV photogrammetry, Lightweight Revolving Laser Scanner (ZEB) and DGPS has been developed in order to characterize aeolian morphologies and changes. This methodologic paper presents the acquisition protocols and, as results, the methods used in order to determine some relevant dune state descriptors. Photogrammetric and UAV LiDAR acquisitions offer the possibility of a) identification and mapping of the aeolian active areas and morphologies, b) centimetric quantification of diachronic aeolian erosion and deposition, c) determination of rate of change and displacement of dunes, and quantification of the sand volume affected by aeolian transport, d) quantification of erosion induced by human trampling. Finally, Hand Laser (ZEB) is a complementary tool. It gives the possibility of the characterization and analysis of changes of small size aeolian morphologies (blowout...) and highly sensitive areas at a scale never realized before.
\end{abstract}

Keywords : Dune, aeolian processes, UAV, Hand Laser, LiDAR, photogrammetry

\section{Introduction}

The monitoring of coastal dunes evolutions in a context of climate change is a major issue for assessment of coastal hazards. While shoreline retreat and beach erosion are generally well characterized within coastal observatories, the monitoring of dunes fields and of the aeolian processes are more neglected (Le Mauff et $a l$. 2018). During past years, the use of photogrammetry acquired by UAV shows an increasing number of uses in different domains (Mancini et al. 2013). The development of small and light LiDAR sensors open the possibility of LiDAR acquisition by UAV. At the same time, small handheld lasers have been developed. Now, they are reaching a stage of maturity (Dewez et al. 2017) making them operational for acquisition in open coastal areas. This methodological paper presents protocols and, as results, methods developed for the characterization of dunes, of aeolian morphologies and for quantify slight changes induced by aeolian processes. 
Garcin, Desmazes, Nicolae-Lerma, Gouguet, Metereau (Preprint 2019)-Contribution of LRLS, UAV, LiDAR...

\section{Study sites}

The first site (La Pareée Grollier) is located on the Atlantic coast of western France (Pays de Monts, Vendée). The Pays de Monts is covered by an Holocene dune system on seaside and marshes landward. From beach to land, it is observed (a) longitudinal foredunes (up to $130 \mathrm{~m}$ large and 5-8 $\mathrm{m}$ high), (b) digitated-shaped parabolic dunes (up to 10-13 m high) and (c) large overlapping digitateshape parabolic-dunes (up to $18-25 \mathrm{~m}$ high) (d) marshes. The investigated area focus on the beach and seaward foredune ( $1.15 \mathrm{~km}$ by $0.6 \mathrm{~km}$, surface area around $60 \mathrm{ha})$.

The second site La Coubre (Charente-Maritime, France) is $150 \mathrm{~km}$ at south of La Parée Grollier. It is a wide $(3 \mathrm{~km}$ ) and high dune system (up to $50 \mathrm{~m}$ ) covered by a pine forest. The foredune results from fixing works realized during the nineteenth century. It is well developed with a wideness between 75 $\mathrm{m}$ to $200 \mathrm{~m}$ and an elevation around $15 \mathrm{~m}$ NGF. This foredune is highly sensitive to aeolian processes since the 2013-2014 storms cluster. The area investigated is around $60 \mathrm{ha}$ ( $1.2 \mathrm{~km}$ by $0.5 \mathrm{~km}$ ).

\section{METHODS}

Four methodological objectives were targeted:

1) how to accuratly characterize dune changes at a yearly scale,

2) to compare results obtained using several techniques (accuracy),

3) to define in which these methods could be complementary and useful for an accurate characterization of dune and aeolian processes at one date,

4) to determine in what these methods could be useful stakeholders in charge of management of coastal dunes systems.

Characterization of the dunes morphology and detection of changes were investigated in two phases: (i) a diachronic UAV photogrammetric acquisitions associated with dense DGPS measurements (October 2015 and 2016) during low neap tides (La Parée Grollier); (ii) A synchronous acquisitions of UAV photogrammetry, UAV LiDAR, Lightweight Revolving Laser Scanner (ZEB) and dense DGPS measurements realized in June 2018 (neap tide; La Coubre).
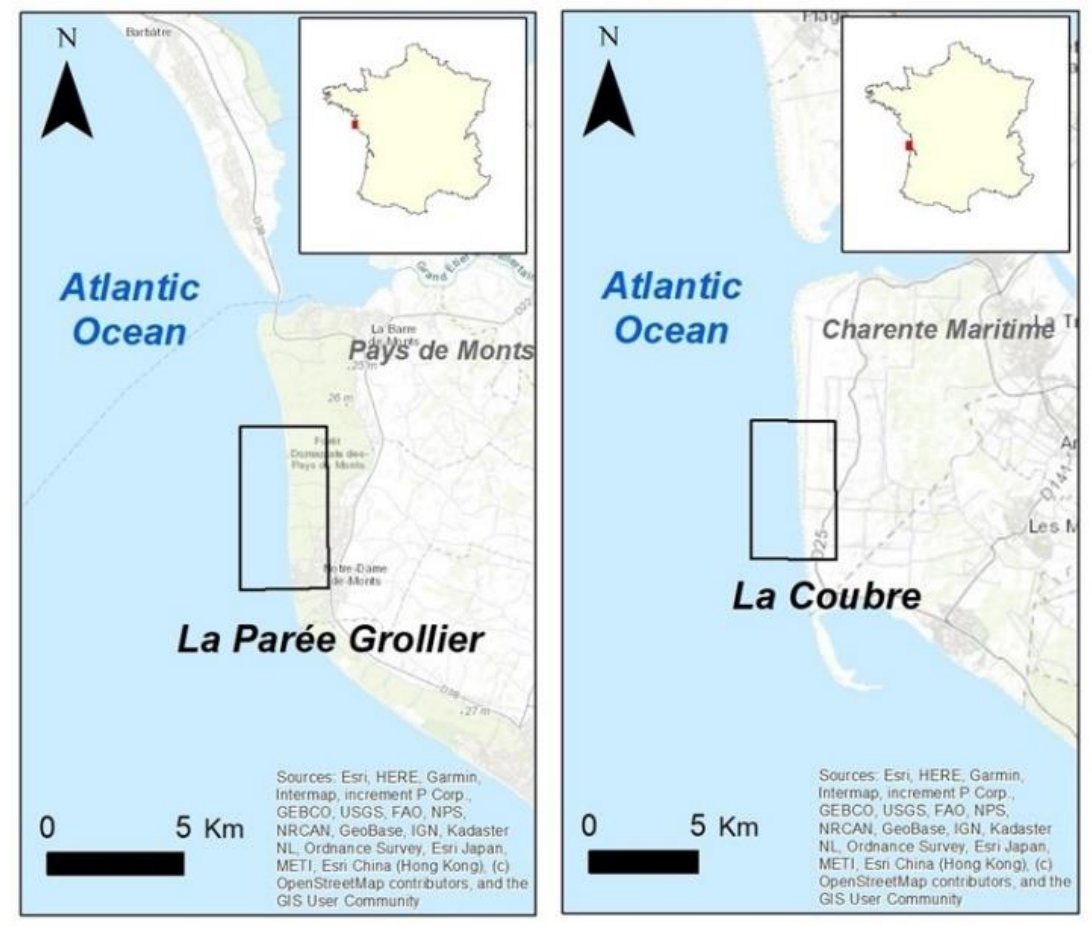

Figure 1. Location map of La Parée Grollier and La Coubre sites 
Garcin, Desmazes, Nicolae-Lerma, Gouguet, Metereau (Preprint 2019)-Contribution of LRLS, UAV, LiDAR...

\section{UAV photogrammetry}

On the La Parée Grollier site, two UAV photogrammetric acquisitions were realized at low water during October neap tides ( 2015 \& 2016) operated by AzurDrone company. The investigated area extends from the sea limit at low tide to several ten of meters inside the parabolic dunes covered by pines forest.

The UAV used is a fixed wing drone (AVEM from Aeromapper); camera was a Sony A5100 with 24 MP of resolution. The post-processing of images was realized with Photoscan (C Agisoft). Positioning residual errors was $4 \mathrm{~cm}$ and $6 \mathrm{~cm}$ respectively in 2015 and 2016. Two colorized 3D point clouds were generated for each year: a high resolution one (around $3 \mathrm{~cm}$ ) with 268.7 millions of points and a second one (resolution around $10 \mathrm{~cm}$ ) containing around 60 millions colorized points (.las file format). The processing of the 3D point clouds generated an ortho-photography with a $3 \mathrm{~cm}$ pixel and two DSM at 0.1 and $0.2 \mathrm{~m}$ grid size (Geotiff file format).

On "La Coubre" site (2018) the UAV used was a multirotor octocopter (Fox8HD from OnyxStra) operated by Avion Jaune company, camera was a 24 MP ILCE6000 from Sony. The post-processing of images was realized with Correlator3D (C Simactive). An ortho-photography at $2 \mathrm{~cm}$ of resolution have been generated (OrthoVista, (C) Inpho) and two DSM at $5 \mathrm{~cm}$ and $8 \mathrm{~cm}$ of resolution.

\section{UAV LiDAR}

On La Coubre site a synchronous acquisition by LiDAR and photogrammetry was realized (2018). The LiDAR sensor was a YellowScan Surveyor (sensor Velodyne Puck, GNSS, inertial central by Applanix). The 3D point cloud generated contains around 240 Millions of points with a precision of $5.4 \mathrm{~cm}$. A classification of points in two classes have been done discriminating soil (sand) from vegetation points thanks to (C) TerraSolid software. This cloud was used to generate a DSM (using both classes) and a DEM (using only soil points class) at $5 \mathrm{~cm}$ of resolution.

\section{Lightweight Revolving Laser (ZEB)}

Three small aeolian morphologies on the La Coubre site where investigated by a pedestrian operator using a lightweight revolving laser (ZEB-Revo (C GeolSlam). Ten to thirteen targets georeferenced with a centimetric DGPS have been used for georeferencing the point clouds (see below). Post processing was realized with GeoSlam Desktop and georeferencing with open source CloudCompare softaware (C CloudCompare.org). Clouds contains around respectively 13.7, 24.2 and 17.2 millions of 3D points.

\section{DGPS}

On La Parée Grollier site, sixteen targets localized with centimetric PPK DGPS (Trimble GeoX7) have been used for images processing $(2015,2016)$. Moreover, numerous DGPS measurements on the foreshore, the beach and the dunes have been realized at the same time in order to evaluate the accuracy of photogrammetric results (1579 points in 2015, 1278 in 2016 points). On La Coubre site, 1088 DGPS measurements have been realized. Ten of them were used as target for UAV LiDAR and photogrammetric processings. Others DGPS measurements were done for cross-shore and long-shore profiling and for mapping of morphological indicators (coastline, dune crest, blowouts limits, etc.). These points were also used to analyze the accuracy of DEMs generated by photogrammetry and by LiDAR against DGPS measurements. 
Garcin, Desmazes, Nicolae-Lerma, Gouguet, Metereau (Preprint 2019)-Contribution of LRLS, UAV, LiDAR...

\section{RESULTS \& DISCUSSION}

\section{Dune Land cover mapping}

Land cover is a good indicator of the morpho-ecological equilibrium of the dune. Bare sand indicates generally active areas prone to Aeolian processes (deflation, erosion or deposition). At the opposite, a forested dune is considered as fixed and few affected by aeolian processes. Between these two categories, the vegetation density is relatively low and these areas are easily degraded by human activities (uncontrolled car and pedestrian tracks, trampling, etc.), rodent burrows and other external factors. The changes of state from vegetated to unvegetated indicate most of the time a dune degradation.

Non-vegetated sandy areas have been automatically extracted from ortho-photography (La Parée Grollier) using a simple algorithm based on colorimetry and intensity developed specifically (fig.2). On the La Coubre site, we used also the classification of type of soil directly associated with each point from LiDAR data (fig.3). Applying one of the both methods on diachronic high frequency acquisitions give access to accurate mapping and monitoring of dune degradation and of aeolian activity.

\section{Dunes \& aeolian morphologies identification}

High resolution DEM, DSM (from LiDAR and photogrammetry) associated to the ortho-photography offer the possibility to map and to characterize the dune system on large areas with centimetric accuracy. Successive profiles done at a low spacing distance give the opportunity to analyze the longshore change of the seaside foredune relative to dune morpho-ecological cycle (Hesp 2002; fig.4). Hotspots of fragility potentially affected by breaching are detectable (for example narrowing of low foredune). For example, at La Coubre, 52 small (plurimetric) aeolian morphologies have been identified (32 blowouts, 10 breaches, 10 depositional lobes; fig. 5). Several descriptors of these morphologies (fig.6), useable by stakeholders to determine the need of remediation action, can be extracted automatically from data derived from LiDAR or photogrammetry (maximum and minimum elevations, area, altitudinal range, slopes, distance to the high tide limit...).

\section{Detection and quantification of changes}

A detection of changes within dune at a centimetric scale and at a various temporal scale (event, season, year...) can be done by differential diachronic DEM/DSM (UAV Lidar or photogrammetric). This approach offers the possibility to detect and to map at high resolution negative and positive elevation changes between two dates. A positive change is related either to a deposit of sand, to the appearance of vegetation or finally to a higher vegetation at the second date. As exemple, the fig. 7 shows changes between 2015-2016. The high resolution of the results allows detection and quantification of erosion (fig.7, B) or accretion in aeolian morphologies, foredune reconstruction or establishment (fig. 7, C), effects of trampling (fig. 7, A) on uncontrolled pedestrian tracks (fig.7) and natural or human induced vegetation degradation (fig.7, A; fig. 8). 
Garcin, Desmazes, Nicolae-Lerma, Gouguet, Metereau (Preprint 2019)-Contribution of LRLS, UAV, LiDAR...

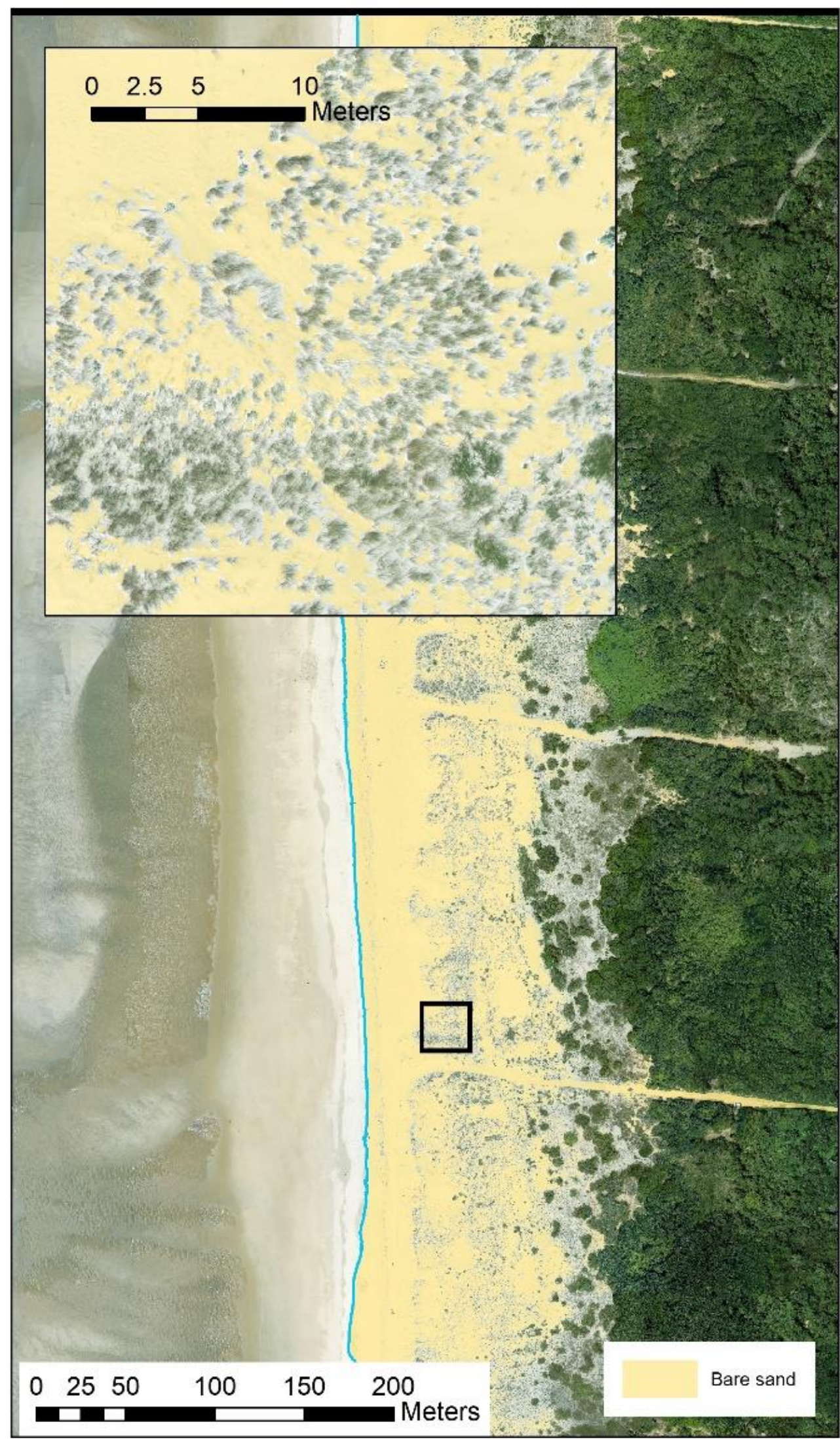

Figure 2. Map of bare sand (yellow) generated by processing of orthophoto at $2 \mathrm{~cm}$ of resolution indicating areas prone to aeolian processes 
Garcin, Desmazes, Nicolae-Lerma, Gouguet, Metereau (Preprint 2019)-Contribution of LRLS, UAV, LiDAR...

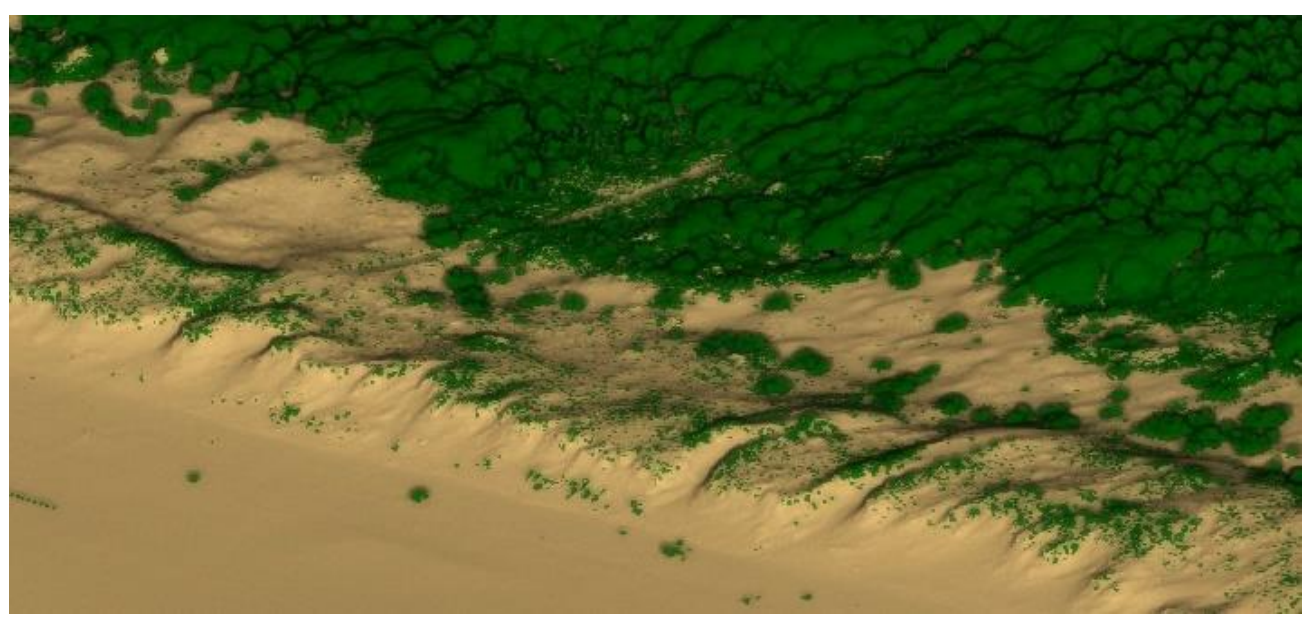

Figure 3. 3D view of UAV LiDAR cloud with classification of soil in two classes (sand and vegetation) - Pines forest in the background, established dune with low vegetation density in the middle and bare sand on foredune and aeolian morphologies

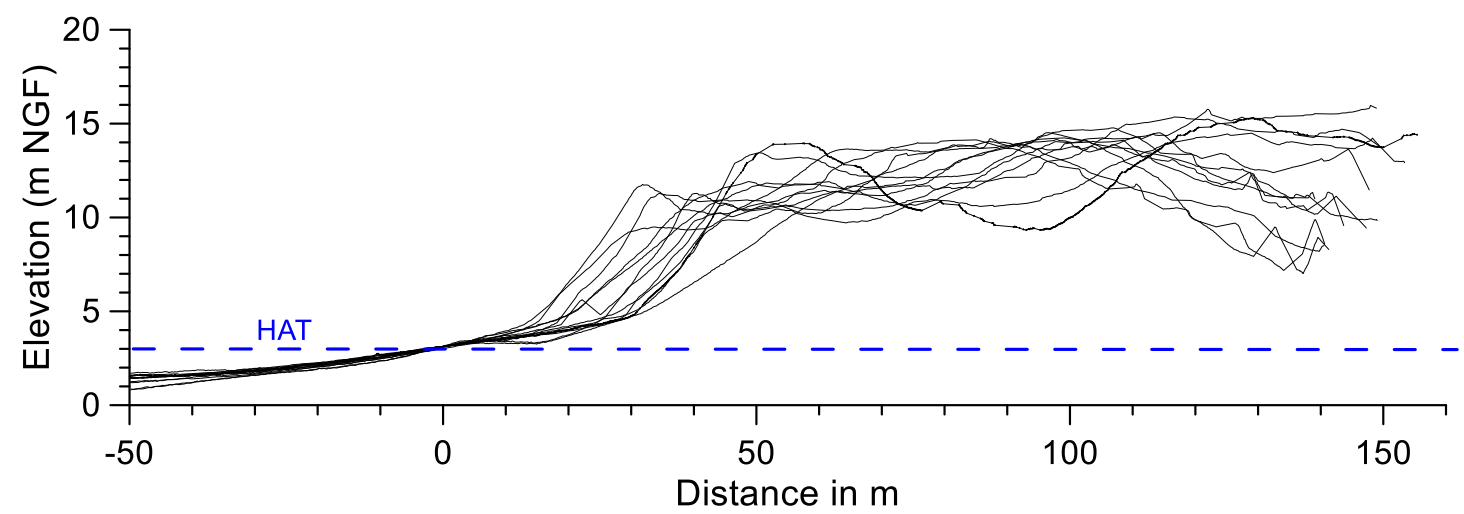

Figure 4. Foredune cross-shore profiles at La Coubre (from 2018 photogrammetric point cloud) illustrating their longshore variability

\section{Characterization of small aeolian morphologies}

Field lightweight revolving laser (ZEB) acquisitions on aeolian morphologies show that 3D point clouds obtained have a higher resolution and accuracy than others acquisition tools on these complex objects (fig. 9). It offers a very accurate description of the sandy morphologies (even a decimetric scale) with the possibilities of monitoring subtle changes between two dates and give the way to monitor morphologic changes in relation with marine erosion and windy events. Moreover, vegetation characteristics (density, height...) can be extracted from the point cloud. On small and complex morphologies highly sensitive to aeolian processes, the ZEB offers a better description and characterization of state and changes than other sensors like UAV LiDAR, fixe laser and photogrammetry.

\section{Evaluation of the volume of sand eroded in the blowouts}

An evaluation of the volume of sand eroded in blowouts and breaches in the foredune has been done by computing the differential volume between today and a reconstructed DEM (i.e. without blowouts; fig. 10). Two method of interpolation (linear and kriging) have been used based on DEM points outside each blowout. As example, eroded volume of a single trough blowouts $\left(n^{\circ} 6\right)$ give us a sand volume of $530 \mathrm{~m}^{3}$ with linear interpolation or $505 \mathrm{~m}^{3}$ with kriging. This approach was extended to all existing blowouts in La Coubre site. Total volume of eroded sand using linear interpolation method is around 
Garcin, Desmazes, Nicolae-Lerma, Gouguet, Metereau (Preprint 2019)-Contribution of LRLS, UAV, LiDAR...

$7700 \mathrm{~m} 3$ for one $\mathrm{km}$ fore-dune length. This value corresponds at the estimation of the volume eroded since the apparition of each blowout.

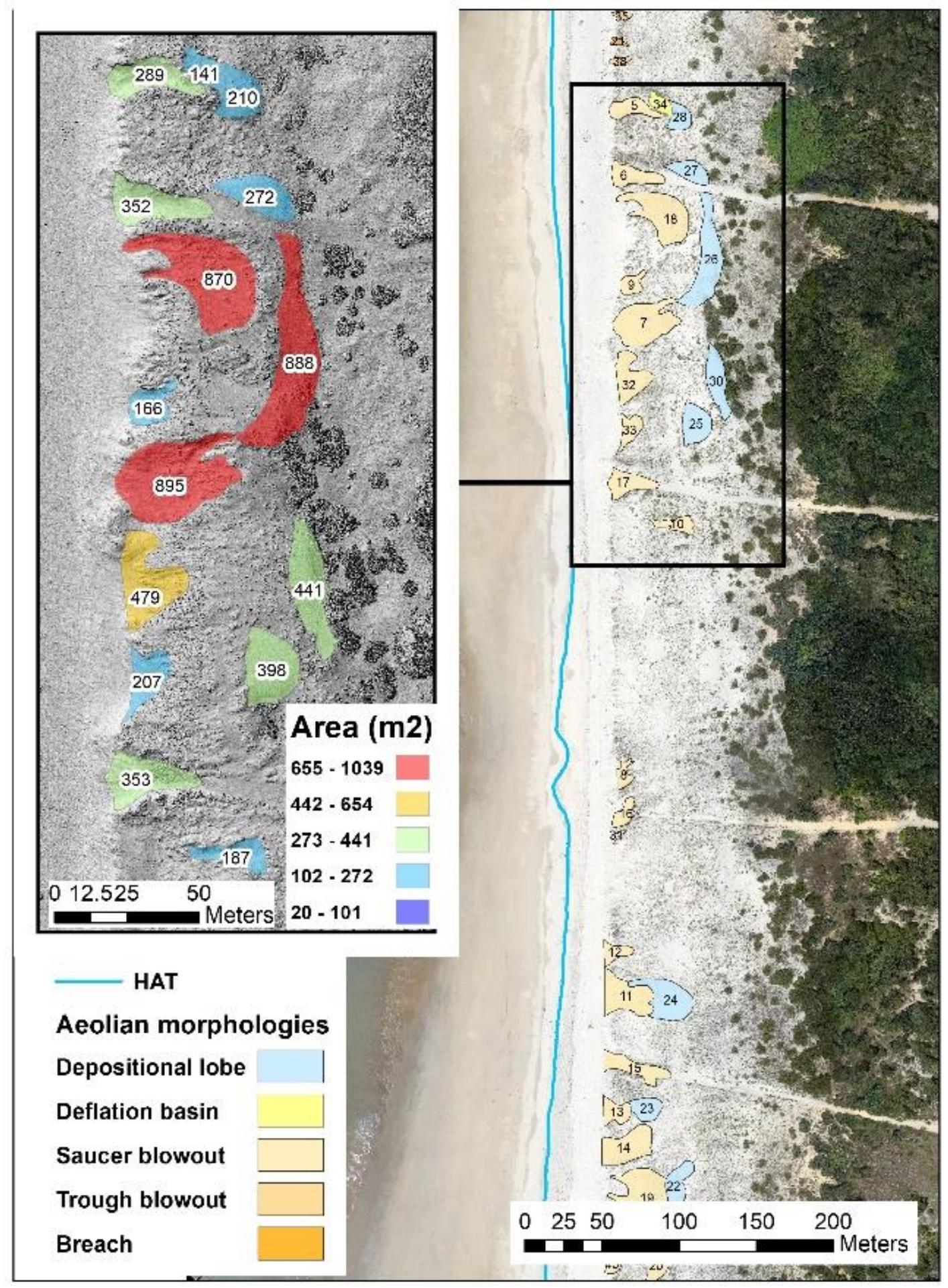

Figure 5. Map of Aeolian morphologies and extraction of their relevant descriptive parameters: area, altitudinal gradient, average elevation, distance to the Highest Astronomical Tide limit. Diachronic analysis of these parameters offer the possibility to quantify with accuracy changes at a high temporal resolution and to determine the evolution trend 
Garcin, Desmazes, Nicolae-Lerma, Gouguet, Metereau (Preprint 2019)-Contribution of LRLS, UAV, LiDAR...
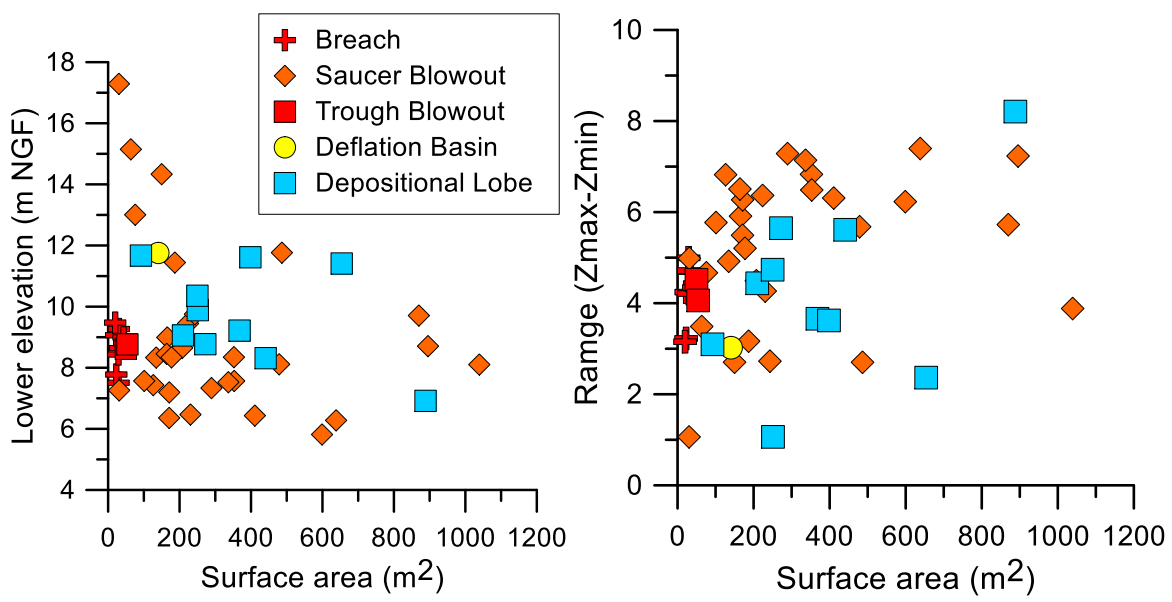

Figure 6. Plots of descriptive parameters by type of aeolian morphologies extracted from UAV data (La Coubre)

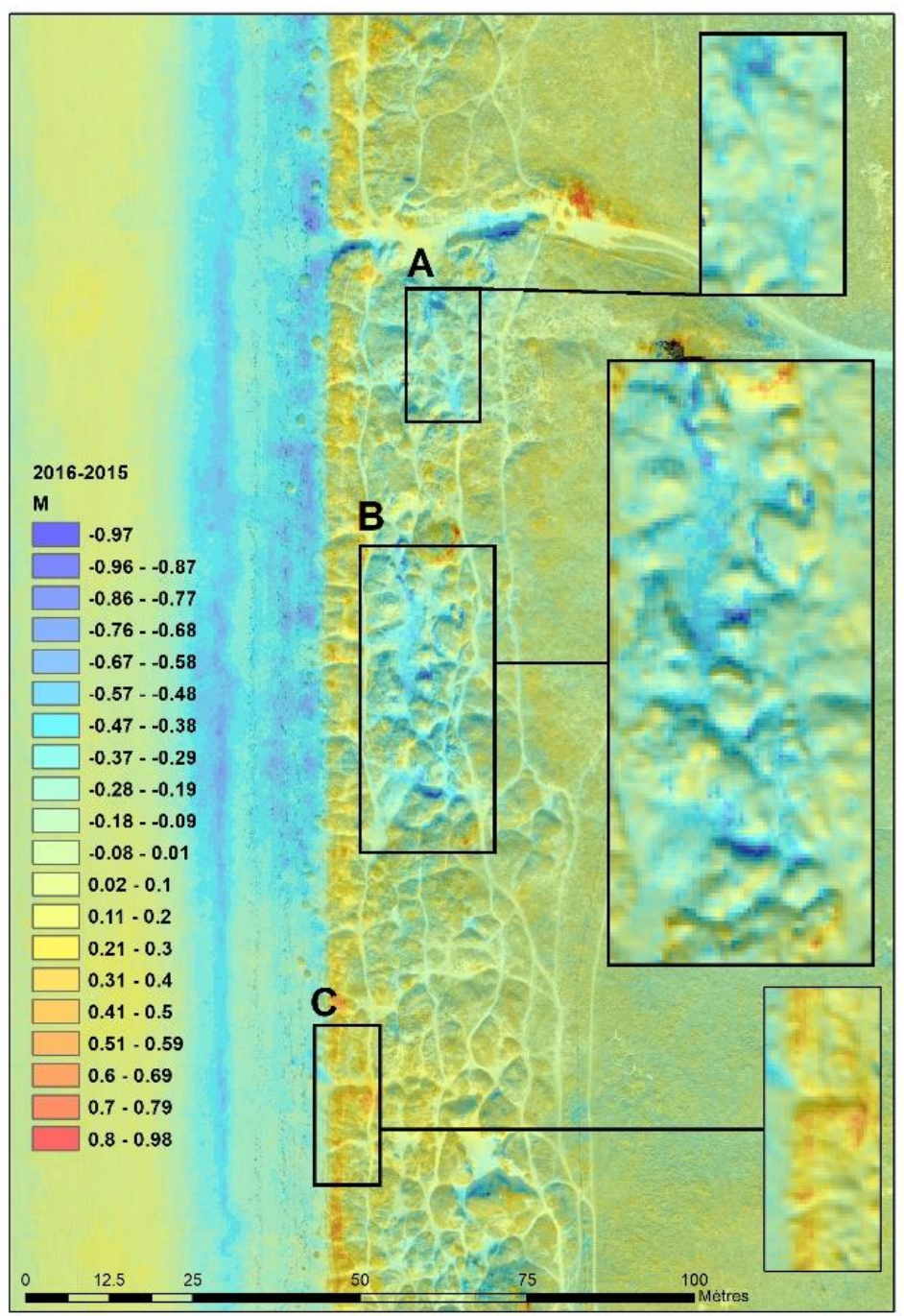

Figure 7. Quantification of yearly changes in the dune complex at La Parée Grollier by differential DEM Negative values in blue, positive values in yellow to red. (A) Quantification of the impact of trampling, (B) Erosion due to destruction of vegetation, aeolian processes and trampling, $(C)$ Increasing vegetation density in a establishing dune toe. Left: The beachface shows a negative sediment budget while foreshore is slightly in 
Garcin, Desmazes, Nicolae-Lerma, Gouguet, Metereau (Preprint 2019)-Contribution of LRLS, UAV, LiDAR...
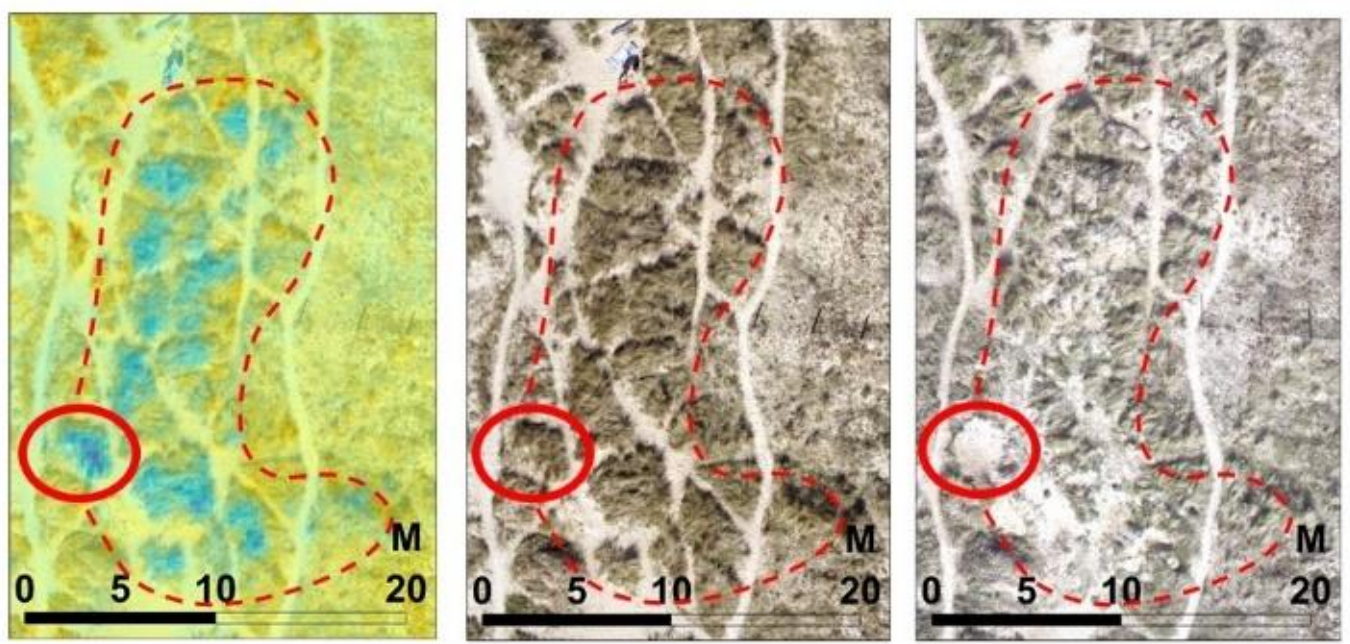

Figure 8. Detection of vegetation degradation due to human presence (left: differential DEM, middle 2015, right 2016) Red dashed line indicates the affected area mainly trampling and vegetation clearing (red circle)
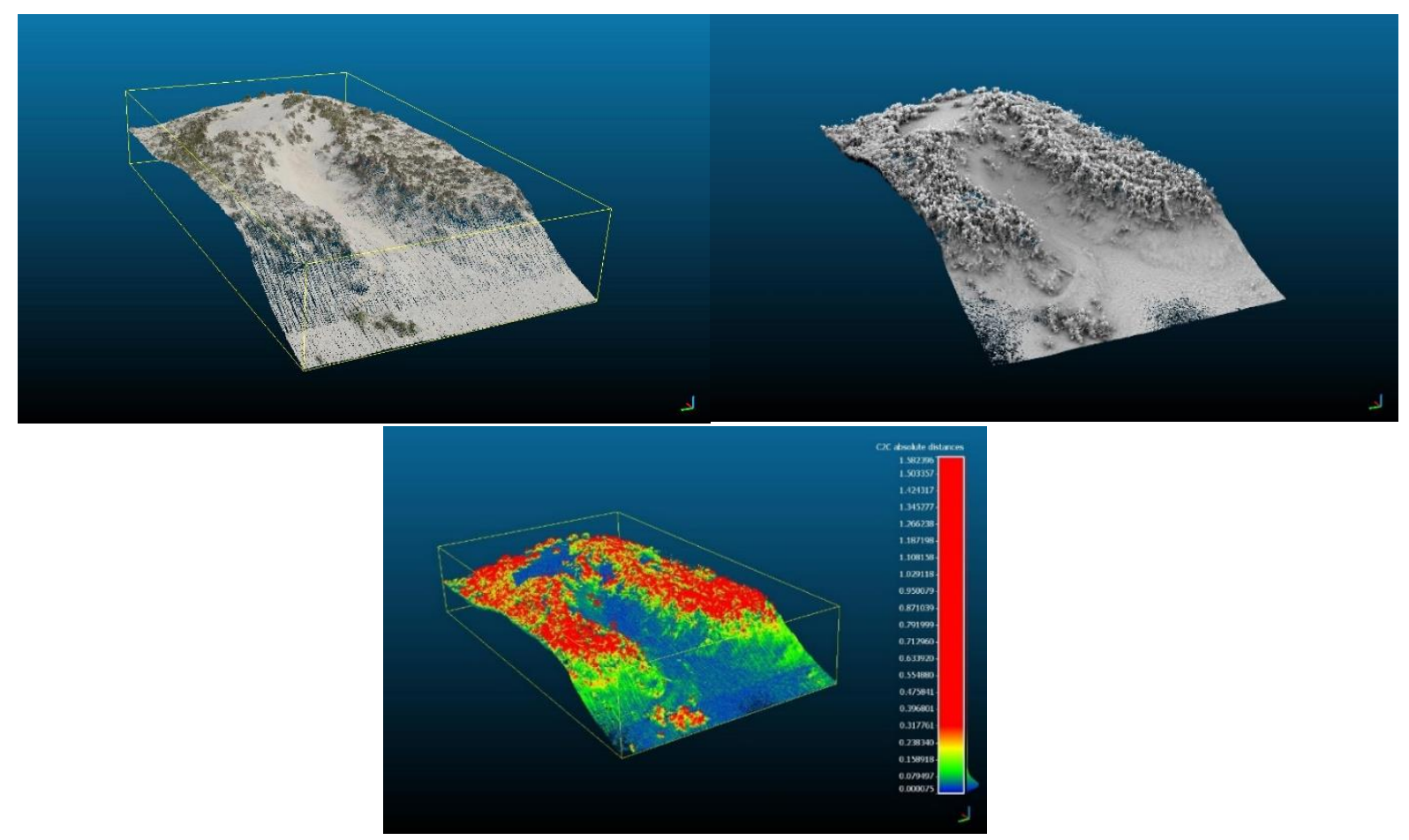

Figure 9. Comparison of point cloud acquire by UAV LiDAR (top left), ZEB (top right) and 3D point clouds (bottom) comparison. The differences are due to a better restitution of the vegetation and of the slopes in the ZEB cloud due to the higher number of measurement points and acquisition method
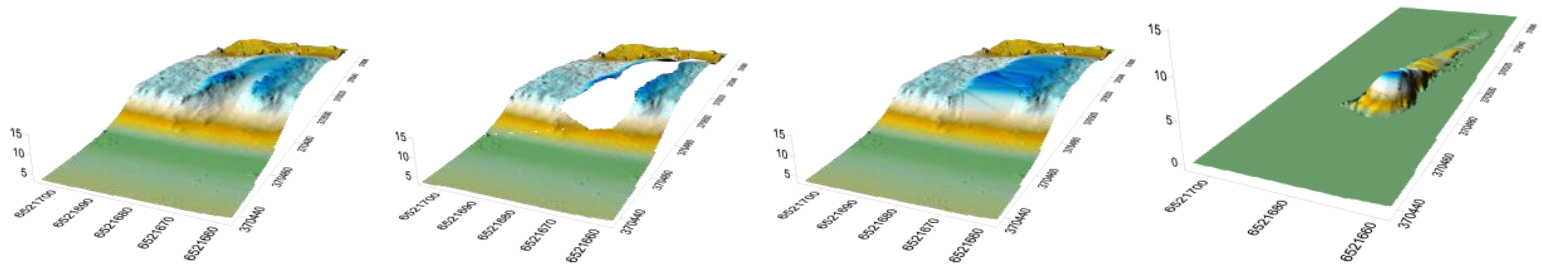

Figure 10. Four steps evaluation of a blowout volume. From top left to bottom right: today topography, without blowout, reconstructed topography, residual volume. 
Garcin, Desmazes, Nicolae-Lerma, Gouguet, Metereau (Preprint 2019)-Contribution of LRLS, UAV, LiDAR...

\section{CONCLUSION}

UAV photogrammetry and LiDAR are adapted tools for characterization and detection of dune change. High frequency acquisitions, achievable at moderate cost, give way to a high resolution monitoring of aeolian processes at a large scale. Nevertheless, some constraints must be taken into account for an UAV acquisition:

1) The meteorological conditions and more particularly the wind speed is a discriminant factor on the feasibility of the acquisition at one specific date and on quality of results due to vegetation movements in windy condition,

2 ) the number of targets used for georeferencing must be appropriate,

3) georeferencing must be done very accurately to ensure good positioning and geometric corrections of point clouds and DEMs. This is particularly important when a diachronic analysis is performed with different sensors.

The ZEB is a versatile tool that is very efficiency for acquisition on small and highly sensitive aeolian morphologies on the field and thus is complementary to UAV sensors. Using a multi-sensor approach and the methods proposed offer the possibility of an in depth analysis of dune morphologies, changes and aeolian processes at a resolution unfeasible before. This multi-sensor approach make it possible to catch some quantitative descriptors which help stakeholders to determine the aeolian areas in need of monitoring and remediation actions.

\section{ACKNOWLEDGEMENTS}

This work was funded by BRGM (AP18DRP017, RP19DRP004) and ONF (Ephedra project). Thanks to Sylvain Yart (BRGM) for field ZEB acquisitions.

\section{LITERATURE CITED}

Dewez T., Yart S., Thuon Y., Plat E. (2017) - Toward cavity-collapse hazard maps with Zeb-Revo handelhd laser scanner point clouds. The Photogrammetric Record.DOI: 10.1111/phor.12223

Hesp P. (2002) - Foredunes and blowouts : initation, geomorphology and dynamics. Geomorphology, 48 , p. $245-268$

Le Mauff B., Juigner M ., Ba A., Robin M., Launeau P., Fattal, P.- (2018) - Coastal monitoring solutions of the geomorphological response of beach-dune systems using multi-temporal LiDAR datasets (Vendée, France), Geomorphology (2018), doi:10.1016/j.geomorph.2017.12.037

Mancini F., Dubbini M., Gattelli M., Stecchi F., Fabbri F. et Gabbianelli G. (2013) - Using Unmanned Aerial Vehicles (UAV) for High-Resolution Reconstruction of Topography: The Structure from Motion Approach on Coastal Environments. Remote Sensing, 5, p. 6880-6898 